\title{
AS PRÁTICAS DOS PSICÓLOGOS EM AMBULATÓRIOS DE SAÚDE
} MENTAL THE PRACTICES OF PSYCHOLOGISTS IN MENTAL HEALTH AMBULATORIES

\author{
Shyrley Bispo Guimarães, Isabel Fernandes de Oliveira e \\ Oswaldo Hajime Yamamoto \\ Universidade Federal do Rio Grande do Norte, Natal/RN, Brasil
}

\begin{abstract}
RESUMO
Os profissionais de psicologia têm sido importantes atores nos ambulatórios de saúde mental brasileiros desde a década de 1980. Todavia, tais serviços ainda representam um desafio à consolidação da reforma psiquiátrica. Soma-se a isso a forma vasta como são referidos em portarias ministeriais, o que propiciou uma diversidade de modelos implantados pelo Brasil. A presente pesquisa foi realizada com psicólogos dos ambulatórios de saúde mental de Aracaju-SE, a partir de entrevistas semiestruturadas e análise documental. Objetivou-se estudar as práticas dos psicólogos, bem como quais os limites e potencialidades da participação desses profissionais nos ambulatórios de saúde mental. Verificou-se a predominância da clínica tradicional com ajustes significativos na postura profissional e no trato com os usuários, além de poucas ações interdisciplinares. Os principais desafios apontados foram o fortalecimento do trabalho em rede, além da necessidade de responsabilização por parte de outras categorias profissionais pelo cuidado em saúde mental.
\end{abstract}

Palavras-chave: atuação do psicólogo; ambulatórios de saúde mental; reforma psiquiátrica; serviços substitutivos; entrevistas semiestruturadas.

\begin{abstract}
Psychology professionals have been playing important roles in the setting of Brazilian mental healthcare ambulatories since 1980s. However, the services offered by these centers still represent a challenge to the consolidation of psychiatric reform. Added to this, there is a wide form of treatment of these issues by Brazilian policy, which provide a variety of models between the ambulatories. This study was conducted with psychologists, workers of mental healthcare ambulatories in Aracaju-SE, and aimed investigate their practices, challenges and limits. It was done a documental analysis, and interviews with a semi-structured instrument. It was found a predominance of the traditional clinical settings, with pertinent adjustments in the professional posture for dealing with users of these services, and lack of interdisciplinary actions. The main challenges identified were the strengthening of professional networking, plus the need of sharing responsibility with other professional groups for mental health care.
\end{abstract}

Keywords: psychologist practice; mental healthcare ambulatories; psychiatric reform; substitute services; semiestrutured interviews.

\section{Introdução}

Em documento recente do Ministério da Saúde (2010), os ambulatórios de saúde mental foram considerados um desafio à consolidação dos pressupostos da reforma psiquiátrica. Ainda nesse documento, colocou-se a dificuldade de articulação desses locais com os demais serviços de saúde mental, além da baixa resolutividade aos casos atendidos. Outros impasses relacionados aos ambulatórios de saúde mental são a falta de um banco de dados confiável e, por conseguinte, alguns prejuízos nos repasses financeiros advindos do Ministério da Saúde. Parte considerável do problema pode ser creditada à diversidade de modelos implantados em relação aos recursos humanos, estrutura física e oferta de ações, devido à falta de diretrizes claras nas portarias ministeriais. Nessa seara, são urgentes estudos que enfoquem experiências locais, que permitam comparar com outras redes de saúde, bem como propiciar o aprimoramento dos documentos e portarias e a geração de mais recursos públicos. 
Considerados serviços de média complexidade e portando equipes com no mínimo duas especialidades diferentes, os ambulatórios de saúde mental têm sido historicamente importante palco de atuação dos profissionais de psicologia. As práticas do psicólogo em ambulatórios de saúde mental no contexto da reforma psiquiátrica configuram um tema ainda pouco explorado. Constitui-se como objetivo principal deste estudo a análise das práticas dos profissionais de psicologia nas Referências Ambulatoriais em Saúde Mental de Aracaju-SE. De modo específico, pretendese: caracterizar as ações ofertadas pelos psicólogos; verificar se há ações realizadas em parceria com outros profissionais e como elas ocorrem; verificar os impactos produzidos pelas Referências Ambulatoriais em Saúde Mental no fluxograma da rede de saúde.

Costa-Rosa (2006) e Yasui e Costa-Rosa (2008) afirmam que a abertura dos ambulatórios de saúde mental tanto possibilitou a reversão de uma rede de assistência curativista e calcada nas internações como contribuiu para a criação de novas demandas para atendimento em consultório. Esses serviços abrigaram duas lógicas de funcionamento contrastantes e, ao mesmo tempo, resultantes da convergência dos movimentos de reforma psiquiátrica e sanitária: o modo asilar e o modo psicossocial. Ambos foram analisados a partir de quatro parâmetros: concepções de objeto e meios de trabalho, relacionamento com a clientela, efeitos típicos em termos terapêuticos e éticos e, por fim, as formas de organização institucional.

No que concerne às concepções de objeto e meios de trabalho, o modo asilar caracteriza-se por pouco levar em consideração a existência do sujeito, além de colocá-lo como centro do problema. A equipe de profissionais trabalha de forma isolada e com base na medicalização, já o tratamento é baseado no diagnóstico psiquiátrico e considera-se que há sucesso quando há remissão dos sintomas e controle da crise (Costa-Rosa, 2006). Em contraposição, na lógica psicossocial, busca-se a autonomia do sujeito. O relacionamento com a equipe dista da primeira concepção, pois profissionais, usuários e familiares são convidados a compor o cotidiano dos serviços e tomarem parte nas decisões acerca do projeto terapêutico (Yasui \& Costa-Rosa, 2008). Um exemplo de reafirmação do modo psicossocial é a proposta da clínica ampliada, da Política Nacional de Humanização do Sistema Único de Saúde (SUS). Tal proposta conjuga o trabalho transdisciplinar, uma compreensão do processo saúde-doença que supera o critério diagnóstico a um projeto terapêutico que contemple as necessidades específicas de cada usuário (Ministério da Saúde, 2008a).
Todavia, a presença de apenas um ou dois desses parâmetros não asseguraria uma mudança da lógica de funcionamento do ambulatório, no qual podem coabitar tanto o modelo preventivo-comunitário como resquícios do paradigma hospitalocêntrico e medicalizador (Costa-Rosa, 2006; Yasui \& CostaRosa, 2008). Essa coexistência de modelos ocasionou a dificuldade de diálogo entre ambulatórios de saúde mental e demais serviços substitutivos, evidenciada pela grande quantidade de encaminhamentos, além do longo tempo de permanência dos usuários nesses serviços (Ministério da Saúde, 2010). Parte desses problemas pode ser creditada à necessidade de novas pactuações e de documentos elaborados pelo Ministério da Saúde que versem sobre o funcionamento e organização dos ambulatórios de saúde mental nos municípios brasileiros.

A Portaria $n^{0}$ 224/92 traz algumas diretrizes sobre o atendimento ambulatorial de saúde mental. Conforme essa portaria, a implantação de ambulatórios de saúde mental deve seguir critérios estabelecidos pelos gestores locais (Ministério da Saúde, 1992), o que propiciou a diversificação de modelos no que diz respeito ao espaço físico, podendo ser instalados em unidades básicas de saúde, centros de saúde, ambulatórios especializados, unidades mistas ou hospitais. A equipe técnica de saúde mental pode incluir psicólogos, psiquiatras e assistentes sociais e, ainda, médicos generalistas, enfermeiros, auxiliares e agentes comunitários. Nas ações ofertadas, são citados

atendimento individual (consulta, psicoterapia, dentre outros), atendimento grupal (grupo operativo, terapêutico, atividades socioterápicas, grupos de orientação, atividades de sala de espera, atividades educativas em saúde), visitas domiciliares por profissional de nível médio ou superior e atividades comunitárias, especialmente na área de referência do serviço de saúde. (Ministério da Saúde, 2010, pp. 1-2)

Em 2008, a Portaria $\mathrm{N}^{\circ} 154 / 08$ versa sobre ações de média complexidade na saúde mental, com os Núcleos de Apoio à Saúde da Família (NASF) (Ministério da Saúde, 2008b). É atribuição das equipes multiprofissionais dos NASF o apoio às Equipes de Saúde da Família (ESF) e às Unidades de Saúde da Família (USF), incluindo o matriciamento aos casos de saúde mental. As ações não mais se difeririam em alta ou baixa complexidade, mas conforme o saber e as ações exigidas em cada caso (Yasui \& Costa-Rosa, 2008).

Tendo em vista a relação entre ambulatórios de saúde mental e a proposta de um modo psicossocial (Costa-Rosa, 2006; Yasui \& Costa-Rosa, 2008), os 
profissionais de psicologia se constituem agentes potenciais na média complexidade. Historicamente, a entrada desses profissionais nos ambulatórios de saúde mental foi condicionada pela baixa oferta de psiquiatras. Observou-se uma atuação descontextualizada, acrítica e apolítica, caracterizada pela utilização de teorias e técnicas psicoterápicas independentemente do tipo de instituição, das características e dos valores sociais do público atendido (Barros, 2005; Boarini, 2000; Dimenstein, 1998, 2000, 2001; Oliveira, Dantas, Costa, Gadelha, Ribeiro, \& Yamamoto, 2005; Patto, 1999; Yamamoto, 2003). Investigações anteriores (Ribeiro, 1999; Santos, 2007; Severo, 2009) constataram que são comuns nos ambulatórios de saúde mental a escassez de atividades em equipe, a baixa carga horária do psiquiatra (além de não cumprirem à risca) quando comparada a de outros profissionais, a centralidade no diagnóstico psiquiátrico e na prescrição medicamentosa, além da falta de diálogo com outros serviços da rede de saúde.

Em Aracaju-SE, os ambulatórios de saúde mental constituem um cenário peculiar, a começar pelo reconhecimento nacional da sua rede de atenção psicossocial. Em 2007, o Ministério da Saúde atribuiu a Aracaju o título de terceira melhor cidade do país no que diz respeito ao tratamento dedicado aos portadores de transtorno mental. Ainda que iniciada de forma tardia se comparada a outras localidades do Brasil, somente em meados dos anos 2000 a reforma psiquiátrica no município de Aracaju (Santos, 2006) conferiu importantes mudanças na rede de serviços de saúde mental, descentralizando a demanda do hospital psiquiátrico para o atendimento em serviços substitutivos. Município de médio porte, Aracaju contou com tal vantagem para uma implementação bem-sucedida dos serviços substitutivos em relativamente pouco tempo. Essa nova lógica trouxe consigo um novo fluxograma, dividindo-se da seguinte forma: os casos leves são de responsabilidade das ESF, os casos moderados ficam no escopo das Referências Ambulatoriais em Saúde Mental, os casos severos podem seguir para hospitais psiquiátricos e serem acompanhados nos Centros de Atenção Psicossociais e, por fim, a retaguarda à crise aguda é ofertada no Serviço de Urgência Psiquiátrica. Podem ser considerados casos leves a moderados sujeitos que se encontram em risco de desemprego, doenças subdiagnosticadas ou não diagnosticadas com aumento de risco de cronificação do quadro, propensão ao uso de bebidas alcoólicas, drogas ilícitas, evasão e repetência escolares, prostituição na adolescência e aumento do número de crianças fora da escola (Secretaria Municipal de Saúde de Aracaju, 2004). Consonante ao fluxograma da rede municipal, o documento "Saúde Mental na Atenção
Básica: o diálogo e vínculo necessários" especifica que os casos leves deveriam permanecer no âmbito das ESF (Ministério da Saúde, 2003). Na prática, essa divisão não ocorre, a começar pela maneira vasta como são definidos os casos moderados, tornando difícil a fronteira entre aqueles considerados leves e os severos.

As Referências Ambulatoriais em Saúde Mental estão instaladas em Unidades de Saúde da Família (USF) e funcionam em cogestão com a Rede de Atenção Básica, que cuida dos aspectos administrativos, e a Rede Atenção Psicossocial, que responde à gestão do cuidado ofertado. Cada Referência possui dois psicólogos e um psiquiatra.

\section{Método}

A pesquisa foi realizada em quatro Referências Ambulatoriais em Saúde Mental, que totalizam o quadro de ofertas relativas a serviços de média complexidade em saúde mental na rede de saúde do município de Aracaju-SE. Foram entrevistados sete psicólogos, um do sexo masculino e seis do sexo feminino, nomeados pela sigla P (P1 a P7), referidos no gênero masculino para evitar identificação das falas. Utilizamos um roteiro semiestruturado, que se dividiu em dois grandes blocos, a saber, histórico e funcionamento dos serviços e práticas desenvolvidas pelos profissionais. Também fizeram parte da análise documentos, atas e relatórios de gestão da Rede de Atenção Psicossocial da Secretaria Municipal de Saúde de Aracaju-SE, a fim de compreendermos as diretrizes e organização dos serviços. Na análise das entrevistas e dos documentos, foram investigadas quais ações são previstas pela Secretaria Municipal de Saúde de Aracaju e de que modo a relação entre gestores e trabalhadores interfere na constituição das práticas do psicólogo.

\section{Ações ofertadas}

Apesar de as equipes de saúde mental das Referências Ambulatoriais em Saúde Mental dividirem o mesmo espaço que as ESF, poucas são as ações em conjunto. Para chegar às categorias elencadas, consideraram-se as atividades citadas pelos profissionais, a descrição de sua execução, a frequência semanal e se eram realizadas de forma isolada ou em parceria do psicólogo com outros profissionais. As categorias foram organizadas da seguinte maneira: atendimento individual, grupos, visitas e reuniões com as equipes de saúde da família, acolhimento e ações educativas. 


\section{Atendimento individual (apoio psicológico)}

Os atendimentos individuais correspondem à maior parte da agenda dos psicólogos, perfazendo $60 \%$ das ações ofertadas (três dos cinco dias da semana), o que sinaliza a predominância da clínica tradicional. Todavia, frente à grande quantidade de usuários encaminhados, algumas modificações tiveram de ser executadas. Os psicólogos, então, diminuíram a duração das consultas, aumentaram o intervalo entre elas e optaram por focar as sessões de atendimento individual em questões mais urgentes. No lugar da terapia individual, criaram o "apoio psicológico". P7 nos conta que "as leis de regularidade e de horário semanal não são possiveis, por conta das próprias dificuldades dos próprios usuários de chegarem, de estarem disponiveis todos os dias".

A proposta do "apoio psicológico" refletiu ainda a preocupação em ultrapassar o modelo biomédico, conforme evidenciado no seguinte trecho: " $a$ gente leva um tempo pra perceber mesmo que são dificuldades sociais, da vida da pessoa e não vai conseguir cuidar disso num ambulatório com quatro paredes fechadas e tem que arranjar alternativas pra isso" (P4). Nesta fala aparece a proposta de uma psicologia mais comprometida com o contexto social, resumida por Martin-Baró (1996) ao afirmar que: "Se até o DSM III ... reconhece que todo comportamento envolve uma dimensão social, o quefazer do psicólogo não pode limitar-se ao plano abstrato do individual, mas deve confrontar também os fatores sociais onde se materializa toda individualidade humana" (p. 11).

Apesar de adotarem referenciais teóricos e técnicos distintos, eles, em sua maioria, relacionamse à psicologia clínica. Vale dizer que os entrevistados também foram unânimes ao afirmar que a classificação internacional de doenças (CID) era um dos fatores, mas não o principal para a construção do projeto terapêutico do usuário. A autonomia do usuário em relação à rotina e suas relações familiares e sociais foi outro fator priorizado na decisão de qual tipo de tratamento ofertado. Por exemplo, um usuário que seja portador de esquizofrenia, que tenha preservada uma rede social e familiar e que realize sem dificuldades suas atividades diárias não precisa ser acompanhado num serviço de alta complexidade, como o Centro de Atenção Psicossocial (CAPS). Tal postura corrobora com o modo psicossocial, que traz o sujeito para a condição de protagonista do seu tratamento (CostaRosa, 2006).

Entretanto, foram relatadas dificuldades para conseguir encaminhar os usuários aos demais serviços da rede. P1 nos diz: "Se você não foi descabelada, transtornada, desorientada então não é tido como caso de CAPS. A gente tá como 'n' casos de CAPS aqui”. Por muitas vezes, os serviços de saúde mental deixam de receber o perfil esperado, refletindo falhas no fluxograma e nos critérios de acesso aos serviços. Na prática, nem o CID, nem a autonomia do sujeito servem de parâmetro para o prognóstico, dada a falta de consenso entre os próprios profissionais.

Não obstante os esforços para pôr em prática uma clínica diferente do modelo tradicional, os psicólogos expressaram uma crise constante a respeito do que deveria ser a real função da Referência Ambulatorial e sua relação com os demais serviços da rede de saúde. Sendo serviços de média complexidade, as Referências Ambulatoriais em Saúde Mental assumem um papel intermediário entre a baixa (atenção básica e ESF) e a alta complexidade (CAPS). Outro impasse que vem à tona diz respeito à natureza das ações ofertadas: 0 cuidado no território ou o atendimento em consultório. A opção por priorizar atividades do primeiro tipo, por vezes, impacta na identidade profissional de alguns deles, produzindo angústias. "Ai quando começa a migrar, fazer atividades diferentes, eu também não me sinto à vontade, porque tem um monte de gente em sofrimento, que não tá tendo uma escuta, entendeu?" (P6). Ou seja, mesmo atuando fora do consultório particular, a prática do apoio psicológico parece garantir certo conforto, provavelmente por representar uma ação tradicionalmente característica da profissão.

Mesmo com a preocupação de adotar uma postura diferente e que proporcione o bem-estar dos usuários, os psicólogos continuam a trabalhar isoladamente, refletindo alguns resquícios do modo asilar (Costa-Rosa, 2006): cada um em sua sala, psicólogo e psiquiatra, sendo o prontuário o principal meio de comunicação entre ambos. Alguns profissionais entrevistados também se queixaram dos encaminhamentos inadequados, muitos deles por conta da desresponsabilização de profissionais das equipes de outros serviços. Resumindo essa questão, impera nos ambulatórios a cultura do "chorou, manda pro psicólogo" (P3). A expectativa gerada pelos outros profissionais de uma atuação isolada do psicólogo no ambulatório acaba funcionando como um reforçador na manutenção de tais práticas.

Em linhas gerais, os objetivos do atendimento individual foram: ouvir a demanda, orientar, prestar um atendimento de curta duração e/ou encaminhar para outros serviços que melhor se encaixem na necessidade apresentada pelo usuário. Embora não tenha sido considerada psicologia clínica, nos moldes tradicionais, não se pode afirmar que os psicólogos tenham encampado de fato a clínica ampliada 
(Ministério da Saúde, 2008a) no cotidiano desses atendimentos. Entretanto, são visíveis algumas tentativas em direção a essa última modalidade, a exemplo dos encaminhamentos para outros serviços e demais recursos da comunidade, da superação do critério puramente diagnóstico na definição do projeto terapêutico, do atendimento em parceria com o psiquiatra (um dos entrevistados atendia em conjunto) e da flexibilização da agenda ao priorizar os casos de urgência. Com isso, observamos uma diferença nítida nesse modo de proceder, se comparado à atividade tradicional. Não obstante, é notável um processo ainda em curso na incorporação dessas condutas.

Adiante, será abordada outra ação ofertada pelos psicólogos das Referências Ambulatoriais em Saúde Mental. As atividades grupais se tornaram uma alternativa (ou pelo menos, tentativa) de resolver o descompasso quantitativo entre oferta e demanda.

\section{Grupos}

Depois do atendimento individual, os grupos foram as atividades mais executadas pelos psicólogos. No período em que aconteceu o trabalho de campo, havia grupos em três das quatro Referências pesquisadas. Os psicólogos da quarta Referência afirmaram já terem conduzido grupos anteriormente e que pretendiam retornar com essa atividade, alegando a necessidade do auxílio dos estagiários de psicologia. Foram citadas quatro modalidades: grupo terapêutico, grupo oficina, grupo aberto e grupo fechado.

Embora representem uma atividade em expansão nas Referências Ambulatoriais, uma questão apresentada pelos psicólogos em relação às práticas grupais foi o debate quantidade versus qualidade. Apesar de representar uma alternativa para atender um número maior de usuários, há que se considerar que nem todas as necessidades podem ser atendidas com os grupos. Operando segundo a mesma lógica de produtividade do atendimento individual, os grupos apresentariam ainda a vantagem de atender mais usuários a um só tempo (Oliveira et al., 2005) e urge diferenciar "atender mais pessoas" e "atender melhor". Nesse contexto, é patente a pressão sofrida pelos psicólogos frente à grande procura: " $O$ discurso $d a$ gestão é grupo, mas que é muito mais pela quantidade; já a gente entende que deve ser pela necessidade" (P4).

Outro aspecto que apareceu na análise sobre a oferta e execução dos grupos correspondeu às parcerias entre os profissionais. Dentre as mais bem-sucedidas, merece destaque o grupo-oficina de artesanato com mulheres do território correspondente à Referência Ambulatorial da USF Francisco Fonseca. Além do estímulo à autonomia das usuárias participantes, o projeto destaca-se pela proposta de geração de renda, promovendo mudanças substanciais nas vidas das donas de casa. $\mathrm{O}$ artesanato é produzido coletivamente e vendido em bazares e numa pequena loja situada no território da USF. Uma parte do lucro é repartida entre as produtoras e a outra é direcionada para a compra de matéria-prima. Um detalhe fundamental para que fosse levado adiante é que esse grupo é conduzido pela parceria de psicólogos e da assistente social. Nessa esfera, cabe recordar quando Amorim (2003) e Lobosque (2001) enfatizam a urgência em reinventar e produzir junto com o usuário novas possibilidades para lidar com o sofrimento psíquico. Esse grupo se coaduna com essa visão na medida em que promove uma transformação no cotidiano dessas mulheres, ao tratar de questões psicológicas sem dissociá-las do aspecto social. Torna-se interessante também a participação da psicologia numa visão de sujeito que não lhe é comum, mas que é familiar ao serviço social, a saber, a de cidadão e de sujeito de direitos. $\mathrm{O}$ resgate da cidadania através do trabalho e projetos de geração de renda tem sido um tema bastante discutido e incorporado ao processo de reforma psiquiátrica.

Outro destaque foi o grupo de homens da Referência da USF Anália Pinna, de caráter fechado, sob a perspectiva do Teatro do Oprimido, com a colaboração de um Agente Comunitário de Saúde (ACS). O grupo começou com uma proposta clínica, no entanto, após o psicólogo ter participado de oficinas promovidas pelo Centro de Teatro do Oprimido (CTO) do Rio de Janeiro, a proposta se ampliou para a abordagem dos problemas sociais, compartilhada pelos integrantes. $\mathrm{O}$ grupo de Teatro do Oprimido tem representado uma saída ao trato medicalizante e biologizante às queixas dos usuários (Yasui, 2009). Uma terceira parceria, adotada em todos os serviços investigados, ocorre com estagiários da graduação de psicologia para condução de grupos de orientação cognitivo-comportamental. Um aspecto que comprometia o andamento e continuidade dos grupos era a rotatividade dos estagiários, o que implicava em um recomeço constante das atividades, além da necessidade de (re)criar novos vínculos entre usuários e estagiários.

Existem ainda os grupos de Sala de Espera, comumente de caráter educativo. Os participantes das palestras e atividades interativas são todos aqueles que procuram os mais variados serviços ofertados (consultas, vacinas, distribuição de medicamentos) pelas USFs, que são Referências em Saúde Mental. Sob a supervisão do psicólogo, os estagiários de psicologia e profissionais das ESF são os que põem 
em prática tais ações. Os grupos de Sala de Espera configuram ações potenciais na proposta da saúde mental na atenção básica, na medida em que trabalham um conjunto de necessidades de saúde que o usuário venha a manifestar (Campos, 2007). O projeto rompe com a visão compartimentada do sujeito e da doença mental. Essas ações estão presentes, sobretudo nas Referências das USF Anália Pinna e Francisco Fonseca. O grupo de gestantes e de idosos da Anália Pinna se destaca pela participação de ACS e enfermeiros das ESF. Sobretudo o grupo de gestantes, está sempre se renovando, pois dura em torno de seis meses e desempenha um papel importante no diálogo proporcionado entre saúde mental e atenção básica. Os psicólogos da Referência Ambulatorial levam algumas contribuições na orientação, prevenção e informação para as futuras mães e para os idosos, explorando os enfoques biológico, psicológico e social. É notável o envolvimento do psicólogo com questões de saúde coletiva, ampliando o escopo das ações tradicionalmente ofertadas pela psicologia (Carvalho, Bosi, \& Freire, 2009).

De modo geral, tanto os grupos abertos como os fechados representam atividades potenciais para parcerias entre psicólogos e demais profissionais das USF de referência. A depender do objetivo que os profissionais estejam buscando, determinada modalidade de grupo pode ser mais adequada que outra. Os grupos fechados, por exemplo, sinalizam a oportunidade de um trabalho mais focado e direto com o usuário, pois possuem um número fixo de participantes, temáticas predefinidas e programação com início, meio e fim. Encaixam-se nessa estruturação o grupo de adultos com quadro de ansiedade da USF Anália Pinna e o grupo para adultos com agorafobia, pânico e transtornos de ansiedade da USF do Sinhazinha, ambos com enfoque na terapia cognitivocomportamental (TCC) e com a parceria de estagiários de psicologia. Simultaneamente ao grupo, os usuários recebem atendimento individual. Os grupos abertos têm focado a interação do usuário com a equipe, familiares e outros usuários e recebido orientação sobre prevenção de doenças e promoção de saúde. Contam como desvantagem a rotatividade de usuários e a impossibilidade de trabalhar com demandas mais complexas de saúde mental.

Ainda que nem sempre abordem de forma mais profunda todos os tipos de demanda, os grupos representam um importante elo nas parcerias entre o psicólogo e os profissionais das ESF de cada Referência em Saúde Mental. Já com as ESF das USF referenciadas, essa relação de proximidade se torna um tanto inviável. Na medida do possível, os psicólogos tentam aproximar-se dessas equipes por meio de visitas às USF. Já com as equipes da USF que são Referência em Saúde Mental, uma oportunidade de interação com psicólogos e psiquiatras são as reuniões de equipes. Vejamos como acontecem as visitas e reuniões, bem como quais os avanços e entraves na execução dessas atividades.

\section{Visitas e reuniões com as Equipes de Saúde da Familia}

Emestudoanterior(Arruda,2006)foidemonstrado que a grande quantidade de encaminhamentos às consultas psiquiátricas e ao atendimento psicológico nas Referências Ambulatoriais era resultado pela baixa retaguarda oferecida pela Atenção Básica e pelas ESF aos casos de saúde mental. Ao sinalizar essa realidade, uma das ações postas em prática pelos psicólogos foram as visitas às USF. O objetivo principal consiste em informar e sensibilizar os profissionais desse âmbito a respeito do fluxograma em saúde mental e do fomento às práticas de cuidado no território (Lancetti, 2008). A ordenação da linha de cuidado em saúde mental e a garantia de um fluxo harmonioso entre os serviços são pressupostos à efetivação do matriciamento, de forma a evitar o inchaço e cronificação dos usuários nos ambulatórios de referência. Na prática, entretanto, ainda "chega de tudo" nos ambulatórios: "Mas na realidade, a gente atende muita gente que tá num nivel de comprometimento maior, muitas pessoas da UBS não se apropriam disso. Muitas vezes, é uma coisa leve, mas mandam esse usuário logo pra cá" (P5).

As visitas dos psicólogos às USFs representaram um avanço, ao considerarmos a hegemonia das práticas tradicionalmente reservadas a essa classe profissional (Dimenstein, 2000) e do modo asilar de cuidar (CostaRosa, 2006). Essas ações significam uma maneira eficiente de reforçar o diálogo com os serviços básicos de saúde e a proposta da saúde mental, lançando o desafio de "atender de portas abertas o que o hospital psiquiátrico atendia de portas fechadas" (Lancetti, 2008, p. 48).

Não obstante, na prática, há dificuldade para garantir adesão e responsabilização das ESF pelo atendimento aos casos de saúde mental. Lidar com a rotatividade de profissionais e gerentes - estes últimos, em sua maioria, são cargos comissionados - é o principal desafio apontado pelos psicólogos para a continuidade das ações. Em consequência, há necessidade de repactuar constantemente com a Rede de Atenção Básica, o que acaba acarretando desestímulo por parte dos psicólogos. Sobre isso, nos fala o psicólogo 2: "Essas visitas nas unidades também, toda vez que eu 
vou, sempre me perguntam qual o usuário que deve ser atendido na referência" (P2). Ou seja, a troca constante de profissionais impede que a parceria entre saúde mental e atenção básica aconteça de forma mais consolidada.

O mesmo distanciamento em relação ao cuidado em saúde mental também foi observado no funcionamento das reuniões entre os profissionais da equipe da Referência Ambulatorial (psicólogo e psiquiatra) e ESF. Primeiro, o psiquiatra não comparecia; depois, os espaços foram minguando, possivelmente em decorrência da agenda da atenção básica que muitas vezes é carregada de prazos curtos (ex. campanhas de vacinação, de combate à dengue, etc.). Por outro lado, percebe-se que os psicólogos também não se envolvem com as questões de saúde coletiva.

\begin{abstract}
Antes, toda sexta-feira tinha reunião e tinha nosso espaço, "olha, Doutor Fulano, aquele paciente Tal, que é seu...”, então a gente discutia sobre cada paciente. Hoje essas reuniões não existem. E quando tem, eu não fico, porque é um saco, é pra discutir febre amarela, tuberculose, vitamina $A$ e não tem espaço pra discutir as demandas da saúde mental. Só para as demandas da saúde da família. Porque tem prazo pra isso, prazo pra aquilo e esquecem que a gente é atenção básica também. (P1)
\end{abstract}

Corroborando com a discussão de Yasui e CostaRosa (2008) acerca das dissonâncias entre o modo asilar e o modo psicossocial, é notável a falta de coesão entre os profissionais, tanto dentro do serviço como no âmbito da rede. Aliada à já comentada falta de interesse das ESF pelo objeto de cuidado da saúde mental soma-se a expectativa de que o psicólogo deva exercer suas atividades isoladamente, no consultório. O último fator é evidenciado no acolhimento em saúde mental, o qual costuma ser posto em prática somente (quando não deveria) pelos psicólogos.

\section{Acolhimento em Saúde Mental}

$\mathrm{O}$ acolhimento tem por finalidade o cumprimento do fluxograma da rede de saúde mental e o atendimento adequado às reais necessidades em saúde do usuário (Santos, 2006). A partir dos pressupostos da Política de Humanização do SUS (Ministério da Saúde, 2008a) e do Modelo Saúde Todo Dia (Santos, 2006), que diz respeito ao SUS da cidade de Aracaju, ocorreu a implantação do acolhimento nas Referências em Saúde Mental no ano de 2005. Naquele momento, pretendeu-se reduzir as grandes filas de espera e o incremento da resolutividade da assistência (Secretaria Municipal de Saúde de Aracaju, 2005). Desde então, o acolhimento em saúde mental tem constituído uma ação de caráter obrigatório para os profissionais das Referências, regulada e prevista pela gestão municipal e, ao contrário das demais, sua execução independe da vontade ou disponibilidade dos psicólogos. Como, então, ocorre o acolhimento em saúde mental? As Referências Ambulatoriais em Saúde Mental não recebem demanda espontânea. Dessa maneira, todo e qualquer usuário deve vir encaminhado de algum outro serviço. P5 nos explica como procede:

Então, o acolhimento é você acolher essa pessoa, apresentar a instituição em saúde mental e a rede em saúde mental e a rede de saúde de uma forma geral a essa pessoa. ... pra que você possa ofertar a ela o melhor cuidado, seja na referência ou não. (P5)

Quanto ao papel do psicólogo na realização do acolhimento, esse profissional tem sido o único - quando não deveria ser - responsável por esse procedimento inicial aos usuários encaminhados para atendimento nas Referências. Excepcionalmente, a exemplo da Referência Ambulatorial da USF Francisco Fonseca, a assistente social também aderiu por algum tempo a esse trabalho. Todavia, são estes últimos quem detêm o poder de decisão para definir qual o encaminhamento mais adequado para o usuário. Entretanto, a tomada das decisões acerca do encaminhamento do usuário não necessariamente constaria num indício de autonomia do psicólogo no serviço. Levando em conta as grandes filas de espera, estaria o psicólogo sendo apenas um "secretário do psiquiatra"?

Antes de apontar respostas, alguns fatores devem ser ponderados, como a reduzida carga horária do psiquiatra (20h), além da grande quantidade de encaminhamentos para esse profissional. O psicólogo aparece como uma figura ambivalente na relação com o psiquiatra, pois ele regula e avalia se é caso de psiquiatria ou não. Porém, quando o usuário começa a frequentar as consultas psiquiátricas, o acompanhamento psicológico aparece como terapia complementar à prescrição de psicotrópicos. " $A$ maior parte [que recebe atendimento individual com o psicólogo] é acompanhada pelo psiquiatra também. Do grupo, acho que uns $80 \%$ são acompanhados pelo psiquiatra" (P3). A partir disso, cabe outra pergunta: o que há por trás da relação psicólogo-psiquiatra? A seguir, P3 conta um pouco sobre o contato, na prática cotidiana, entre essas duas especialidades: "Basicamente, ele [psiquiatra] faz atendimento individual, não dá tempo de ele participar de outras coisas" (P3).

Parte-se do ponto de vista de que o trabalho do psiquiatra na Referência em Saúde Mental não se reduz apenas a um problema quantitativo (de falta de profissionais de psiquiatria no mercado), mas sim a uma 
necessidade de transformações na prática profissional e, sobretudo, na lógica institucional. Basaglia (2001) foi categórico ao alertar sobre a necessidade de romper com a relação objetual entre a psiquiatria e seu paciente, fosse por meio da prática diagnóstica ou da prescrição medicamentosa. Compreende-se ainda que o tratamento psicológico deveria desocupar esse espaço secundário e complementar à intervenção psiquiátrica (Yasui \& Costa-Rosa, 2008).

Apesar de o acolhimento depender diretamente do psicólogo, o qual decide sobre os rumos e possibilidades que o usuário terá logo nos seus primeiros contatos com a Referência em Saúde Mental, a saída ou a alta desse usuário estará condicionada à sua avaliação psiquiátrica. Enfim, o psicólogo define quem entra, mas é o psiquiatra quem coordena quem deixa o serviço. $\mathrm{O}$ acolhimento funciona como uma espécie de triagem, uma vez que já é sabida pelos psicólogos a impossibilidade de atender a todos os sujeitos que deveriam receber um suporte desse serviço. Será que o sujeito está recebendo a assistência que deveria? O acolhimento resolve o problema da alta demanda? A fala adiante nos fornece algumas pistas que nos ajudam a refletir essa questão. "A gente não pode assumir uma responsabilidade de que o próprio SUS não dá conta, ele não atende todo mundo, porque não tem recursos para isso" $(\mathrm{P} 1)$. Tal relato aponta o despreparo da rede de serviços para dar conta da demanda. A própria PNH (Ministério da Saúde, 2008a) e seu discurso de otimização da assistência não tocam a fundo nessa questão. Em outras palavras, quando não se consegue prestar assistência adequada a todos, a solução apresentada é a de oferecer um apoio.

A infraestrutura dos serviços ambulatoriais, que conta apenas com os consultórios psicológico e psiquiátrico, e a carga horária reduzida dos profissionais, aliadas à falta de outros especialistas na equipe contribuem significativamente na ausência de um acompanhamento mais intensivo. Vigora a dinâmica da medicalização e atendimento em consultório. Tudo isso nos leva a compreender o porquê de os ambulatórios em saúde mental em Sergipe e no Brasil ainda serem considerados um desafio aos avanços da reforma psiquiátrica (Ministério da Saúde, 2010). Mais uma vez, sobressalta-se a falta de trabalho em equipe, até então, uma única atividade que envolve praticamente todos os profissionais da USF são as atividades educativas.

\section{Atividades educativas}

Foram consideradas atividades educativas: palestras sobre temas específicos (amamentação, depressão, hipertensão, diabetes, etc.), visitas em escolas e festas em datas comemorativas. Apesar de envolver trabalho em equipe (assistentes sociais, agentes comunitários de saúde, enfermeiros, médicos, psicólogos) são esporádicas e não ocupam um espaço fixo na agenda do serviço. P5 comenta sobre tais aspectos: "Essas atividades educativas vão depender da época, do nosso gás, do momento em que a gente tá passando mesmo, da vinculação com a equipe".

A começar pelo tempo despendido na agenda dos profissionais, há uma primazia na execução de ações isoladas. Seja por receio de perder a identidade de psicólogo clínico, seja pela expectativa dos próprios usuários e dos outros profissionais, ou ainda por uma carência de diálogo entre equipes, os psicólogos pouco avançaram com relação ao modo de atuar. Por sua vez, o próprio ambulatório ainda se coloca como um serviço que abarca uma demanda nosologicamente ampla, mas que ainda apresenta tímidos impactos no atendimento prestado aos casos mais graves. Verificase, sobretudo, que apesar da variação e das tentativas de um quadro de ofertas de ações diferenciados, a efetivação dos preceitos da reforma psiquiátrica está para além das mudanças operadas no fazer do psicólogo.

\section{Considerações finais}

Historicamente, as práticas do profissional de psicologia no contexto do ambulatório de saúde mental, sob as premissas da reforma psiquiátrica, resultaram em tímidos impactos na reversão do modelo das internações hospitalares. Também se configurou como característica dos ambulatórios de saúde mental a diversidade de modelos implantados nos municípios brasileiros. No caso das Referências Ambulatoriais em Saúde Mental de Aracaju-SE, os psicólogos desempenham um papel protagonista. Primeiro, porque integram uma equipe reduzida, junto ao psiquiatra. Depois, pelo próprio caráter das ações ofertadas, que extrapolam o modelo clínico tradicional e incorporam uma postura diagnóstica que confere maior espaço a uma análise psicossocial do sujeito, tendo como um de seus efeitos a descentralização do tratamento medicamentoso. Nessa esteira, o tratamento psicoterápico, ainda que breve, e a formação de parcerias com outros setores da comunidade também se incluem como possibilidades de tratamento. Exemplo disso são os grupos terapêuticos. Tais pontos demonstram que não obstante a necessidade premente de expandir as práticas para um viés menos individualista, a perspectiva clínica, sobretudo a psicanalítica, não deve ser descartada. Pelo contrário, esta tem oferecido 
importantes subsídios para a construção de novas práticas que incentivem um cuidado sob a ótica psicossocial e de cunho interdisciplinar.

Entretanto, esse modelo de atendimento encontra-se em construção, visto que algumas dificuldades se impõem na constituição dessas práticas profissionais. Contrariando a proposta do trabalho interdisciplinar (Ministério da Saúde, 2008a; Santos, 2006), ainda são insuficientes as ações realizadas em parceria. A começar pela integração com o psiquiatra, dos sete profissionais entrevistados, apenas um desenvolve um trabalho conjunto. $\mathrm{O}$ psiquiatra continua a desenvolver um trabalho isolado e sua principal ferramenta de comunicação com o psicólogo ainda é o prontuário, padrão já observado em outras pesquisas (Ribeiro, 1999; Santos, 2007; Severo, 2009).

Por outro lado, as atividades grupais significaram uma oportunidade de o psicólogo estabelecer parcerias e, além disso, alargar a oferta de ações e atender mais pessoas. Mostraram-se frutíferas as parcerias com o assistente social e o ACS. Na primeira experiência, conseguiu-se promover mudanças não só na saúde e bem-estar de donas de casa daquela comunidade, mas também no incremento do orçamento doméstico através do projeto de geração de renda. Outra experiência bem-sucedida foi o do Grupo de Homens, promovido a partir da proposta do Teatro do Oprimido, que constituiu um espaço de compartilhamento e (re) construção de questões, que antes eram trabalhadas apenas no atendimento individual. Em ambas, fica patente o esforço dos profissionais de psicologia em buscar parcerias e tratar o sofrimento psíquico de uma forma antimanicomial, libertadora e, sobretudo, cidadã (Amorim, 2003; Lobosque, 2001).

Apesar da variedade de ações ofertadas pelos psicólogos das Referências Ambulatoriais em Saúde Mental, dois pontos merecem ser debatidos: a resistência em não se desvencilhar das práticas já consagradas tradicionalmente pela profissão e a frágil relação com as ESF. Os psicólogos entrevistados ainda centram suas ações nas atividades individuais e nos grupos terapêuticos. Essa transposição de um modelo adotado na clínica privada veio acompanhada de ajustes (e, mesmo com eles, sua atividade não pode ser considerada uma clínica ampliada) na duração das sessões, na frequência dos usuários e até mesmo na profundidade das questões trabalhadas junto ao usuário. Todavia, foram notabilizados alguns passos em direção aos princípios da clínica ampliada (Ministério da Saúde, 2008a), a exemplo da superação do critério puramente diagnóstico como requisito para o usuário ser atendido nos serviços ou ainda das tentativas de responsabili- zação das ESF e das USF referenciadas com os usuários adstritos ao território.

$\mathrm{O}$ segundo ponto diz respeito às dificuldades de diálogo com a rede de atenção básica e com as ESF, reforçando a cultura do "chorou, manda pro psicólogo". As exceções em relação à parceria com as ESF foram os grupos de Sala de Espera, palestras em escolas e festas em datas comemorativas. Tais ações ficaram na pendência do "fôlego", da boa vontade dos profissionais, além de serem raras e não atenderem aos usuários com demanda de saúde mental.

Diante dessas considerações, cabe um último questionamento: qual o alcance do psicólogo nas Referências Ambulatoriais em Saúde Mental? Encontramos um avanço nas práticas, principalmente ao considerarmos que os psicólogos entrevistados vêm aprimorando o modo de cuidar dos usuários, a começar por uma escuta diferenciada desde o acolhimento até as modalidades de atendimento prestado. Não obstante, ainda se mostra como necessidade urgente de fortalecimento da linha de cuidado (Santos, 2006), ou seja, de garantir ao usuário um fluxo por entre os serviços da rede de saúde. Talvez a desinformação e a falta de interesse pela saúde mental, principalmente por parte das ESF, tenham contribuído para que as Referências continuassem prestando um atendimento desintegrado de outros serviços da rede. Este último é apontado como o maior problema enfrentado pelos psicólogos entrevistados e, ao mesmo tempo, algo que foge ao escopo da responsabilidade desses profissionais.

\section{Referências}

Amorim, S. M. (2003). Loucura, política e ética: a formação do psicólogo em questão. In Conselho Federal de Psicologia (Org.), Loucura, ética e política: escritos militantes (pp. 220-229). São Paulo: Casa do Psicólogo.

Arruda, C. A.(2006). Referência Ambulatorial em Saúde Mental e processo de trabalho: uma reflexão sobre produção de cuidado. Trabalho de Conclusão de Curso, Especialização em Saúde Coletiva, Universidade Federal de Sergipe, Aracaju.

Barros, R. B. (2005). A psicologia e o sistema único de saúde: quais interfaces? Psicologia \& Sociedade, 17(2), 21-25.

Basaglia, F. (2001). A instituição negada: relato de um hospital psiquiátrico. Rio de Janeiro: Graal.

Boarini, M. L. (2000). O psicólogo e a desinstitucionalização. In M. L. Boarini (Org.), Desafios na atenção à saúde mental (pp. 65-77). Maringá: EDUEM.

Campos, G. W. S. (2007). Saúde Paideia. São Paulo: Hucitec.

Carvalho, L. B., Bosi, M. L. M., \& Freire, J. C. (2009). A prática do psicólogo em saúde coletiva: um estudo no município de Fortaleza (CE), Brasil. Psicologia Ciência e Profissão, 29(1), 60-73. 
Costa-Rosa, A. (2006). O modo psicossocial: um paradigma das práticas substitutivas ao modo asilar. In P. Amarante (Org.), Ensaios: subjetividade, saúde mental, sociedade (pp. 141168). Rio de Janeiro: Fiocruz.

Dimenstein, M. (1998). O psicólogo nas unidades básicas: desafios para formação e atuação profissionais. Estudos de Psicologia, 3(1), 53-81.

Dimenstein, M. (2000). A cultura profissional do psicólogo e o ideário individualista: implicações para a prática no campo da assistência pública à saúde. Estudos de psicologia, 5(1), 95-121.

Dimenstein, M. (2001). O psicólogo e o compromisso social no contexto da saúde coletiva. Psicologia em estudo, 6(2), 57-63.

Lancetti, A. (2008). Clínica peripatética (Saúde Loucura 20: Políticas do desejo I). São Paulo: Hucitec.

Lobosque, A. M. (2001). Experiências da loucura (Loucura XXI). Rio de Janeiro: Garamond.

Martin-Baró, I. (1996). O papel do psicólogo. Estudos de Psicologia, 1(2), 7-27.

Ministério da Saúde. (1992). Portaria SAS/MS n. 224, de 29 de janeiro de 1992. Brasília: Autor.

Ministério da Saúde. (2003). Saúde Mental na Atenção Básica: o vínculo e o diálogo necessários. Brasília: Autor.

Ministério da Saúde. (2008a). HumanizaSUS: documento base para gestores e trabalhadores do SUS. Brasília: Autor.

Ministério da Saúde. (2008b). Portaria GM n. 154, de 24 de Janeiro de 2008. Brasília: Autor.

Ministério da Saúde. (2010). Saúde Mental em Dados 7. Brasília: Autor.

Oliveira, I. F., Dantas, C. M., Costa, A. L., Gadelha, T. M., Ribeiro, E. M., \& Yamamoto, O. H. (2005). A psicologia, o Sistema Único de Saúde e Sistema de Informações Ambulatoriais: inovações, propostas e desvirtuamentos. Interação em Psicologia, 9(2), 273-283.

Patto, M. H. (1999). Formação profissional, compromisso político e luta antimanicomial. In M. I. A. Fernandes, I. R. Scarcelli, \& E. S. Costa (Orgs.), Fim de século: ainda manicomios? (pp. 109-22). São Paulo: IPUSP.

Ribeiro, P. R. M. (1999). Saúde mental no Brasil. São Paulo: Arte e Ciência.

Santos, R. C. (2006). Saúde Todo Dia: uma construção coletiva. São Paulo: Hucitec.

Santos, Y. F. (2007). O ambulatório de saúde mental no contexto da reforma psiquiátrica em Natal/RN. Dissertação de Mestrado, Universidade Federal do Rio Grande do Norte, Natal.

Secretaria Municipal de Saúde de Aracaju (2004). Programa de Saúde Mental 2004/ Modelo Saúde Todo Dia. Aracaju: Autor.

Secretaria Municipal de Saúde de Aracaju (2005). Relatório de Gestão: rede atenção psicossocial. Aracaju: Autor.
Severo, A. K. (2009). Cronificação nos serviços substitutivos na rede de saúde mental de Natal/RN. Dissertação de Mestrado, Universidade Federal do Rio Grande do Norte, Natal.

Yamamoto, O. H. (2003). Questão Social e políticas públicas: revendo o compromisso social da psicologia. In A. M. B. Bock (Org.), Psicologia e compromisso social (pp. 37-54). São Paulo: Cortez.

Yasui, S. (2009). A atenção psicossocial e os desafios do contemporâneo: outro mundo é possível. Cadernos Brasileiros de Saúde Mental, 1(1), 1-9.

Yasui, S. \& Costa-Rosa, A. (2008). A Estratégia Atenção Psicossocial: desafio na prática dos novos dispositivos de Saúde Mental. Saúde em Debate, 32(78-79-80), 27-37.

Recebido em: 19/01/2012

Revisão em: 2013-07-16

Aceite em: 2013-08-04

Shyrley Bispo Guimarães Mestre em Psicologia pela UFRN. Foi Professora Auxiliar do Departamento de Psicologia da Universidade Federal de Sergipe e Tutora à Distância do Centro de Educação Superior à Distância da UFS. Psicóloga da Secretaria do Desenvolvimento Social e do Trabalho da Prefeitura Municipal de São Cristóvão-SE. Endereço: Rua 10, Número 141, Conjunto Orlando Dantas, Bairro São Conrado. Aracaju-SE, Brasil. CEP 49043-230 Email: shyrleyguimaraes@gmail.com

Isabel Fernandes de Oliveira Isabel Fernandes de Oliveira é Doutora em Psicologia pela USP. Professora do Programa de Pós-Graduação em Psicologia da Universidade Federal do Rio Grande do Norte. Coordenadora do Grupo de Pesquisas Marxismo \& Educação. Email: fernandes.isa@gmail.com

Oswaldo Hajime Yamamoto é Doutor em Educação pela USP. Professor Titular do Departamento de Psicologia da Universidade Federal do Rio Grande do Norte. Coordenador do Grupo de Pesquisas Marxismo \& Educação (CNPq). Bolsista de Produtividade em Pesquisa do CNPq. Email: oswaldo.yamamoto@gmail.com

\section{Como citar:}

Guimarães, S. B., Oliveira, I. F., \& Yamamoto, O. H. (2013). As práticas dos psicólogos em ambulatórios de saúde mental. Psicologia \& Sociedade, 25(3), 664-673. 